\title{
A Thermographic Measurement Approach to Assess Supercapacitor Electrical Performances
}

\author{
Stanislaw Galla \\ Departments of Metrology and Optoelectronics, Faculty of Electronics, Telecommunications and Informatics, \\ Gdansk University of Technology, ul. G. Narutowicza 11/12, 80-288 Gdansk, Poland; galla@eti.pg.gda.pl; \\ Tel.: +48-58-347-21-40
}

Received: 17 October 2017; Accepted: 28 November 2017; Published: 1 December 2017

\begin{abstract}
This paper describes a proposal for the qualitative assessment of condition of supercapacitors based on the conducted thermographic measurements. The presented measurement stand was accompanied by the concept of methodology of performing tests. Necessary conditions, which were needed to minimize the influence of disturbing factors on the performance of thermal imaging measurements, were also indicated. Mentioned factors resulted from both: the hardware limitations and from the necessity to prepare samples. The algorithm that was used to determine the basic parameters for assessment has been presented. The article suggests to use additional factors that may facilitate the analysis of obtained results. Measuring the usefulness of the proposed methodology was tested on commercial samples of supercapacitors. All of the tests were taken in conjunction with the classical methods based on capacitance $(C)$ and equivalent series resistance (ESR) measurements, which were also presented in the paper. Selected results presenting the observed changes occurring in both: basic parameters of supercapacitors and accompanying fluctuations of thermal fields, along with analysis, were shown. The observed limitations of the proposed assessment method and the suggestions for its development were also described.
\end{abstract}

Keywords: supercapacitor; thermovision; analysis; quality

\section{Introduction}

Measurements of systems' properties by non-destructive testing, which also include thermovisional methods, are currently being used in many fields of science and technology. The article focuses on the methodology supporting the state assessment of supercapacitors' samples. Tests and measurements were taken on the basis of commercially available supercapacitors. The development of the measurement methodology was carried out to verify the concept of defining additional parameters, which support the qualitative assessment of the tested capacitors. It was suggested to obtain additional information, regarding the properties of tested capacitors, based on the analysis of thermographic images that were obtained during the charging/discharging cycle while performing classical durability tests.

Implementing thermovisional measurements to tests is related to the current spread of systems that enable measurements of infrared radiation (IR). Presently, the IR observation systems, widely available on the market, are an excellent tool for supporting a variety of developmental research. They allow for obtaining information concerning temperature fields of the surface in a short period of time and, on the basis of field distribution analysis, to conclude on the internal structure. On one hand, the suggested supporting measurement approach, the use of thermal imaging camera, is characterized by lower accuracy of temperature measurement of the examined object than the classically used calorimetric methods described in article [1]. Yet, it allows for more accurate illustration of the temperature field, as well as for indication of thermal energy transfer and the possibility of observing 
the entire sample being tested. The fundamental objective that was set during the implementation of the supercapacitors' non-destructive testing project was the attempt to acquire parameters such as average, maximum temperature increments, and methods of visualizing this areas, by proposed indicators based on sums of temperatures and variation coefficientfor qualitative assessment of examined samples on the basis of obtained thermograms. The article presents the following issues that were to be considered:

- selection of the measurement system including both measurement instruments and the test stand,

- planning the test course sample preparation and the test course itself,

- implementation of data analysis algorithms, along with the selection of parameters obtained from thermovisional measurements that allows to support the quality of supercapacitors,

- measurements and the analysis of usefulness of suggested solutions and parameters supporting the assessment plus their further selection, and

- conclusions, along with information on observed restrictions and proposals for sequential changes.

Recommended additional elements supporting the methodology of assessing the properties of supercapacitors were based on the analysis of temperature field fluctuations in relation to measurements of classical capacitor parameters. Measurements of basic parameters such as: change in capacitance $(C)$ or change in equivalent series resistance (ESR-Equivalent Series Resistance), in connection with information derived from thermographic observations allow for a more comprehensive assessment of supercapacitors. Moreover, the article shows restrictions that were observed while using thermographic methods of qualitative assessment of supercapacitors samples. All of the tests were taken on supercapacitors that are commercially available on the market. The development of thermographic measurements is mainly due to the step-change of the available infrared radiation measurement tools, generally more accessible now in terms of cost and infrastructure. Thermographic assessment is based on tests, which make use of electromagnetic radiation emission in infrared radiation by each body at temperatures above $0^{0} \mathrm{~K}$. As the value of the radiated energy increases with the temperature of the observed object, it allows to measure the temperature by measuring the emitted energy $(M)$. The measured intensity of electromagnetic radiation depends on the temperature and characteristics of the surface of the observed object. Such radiation measurements have found wide application in science and technology, and are based on the practical use of Planck's law. In this paper, a measurement technique called passive thermography was used, which is characterized by the fact that for the period of the test the subject is loaded according to its function and properties and is not subjected to any other external factors. Thermographic observations are based on fluctuations of the surface temperature field of tested samples. Recorded fluctuations in the temperature field allow for both: detecting areas of thermal energy emission and discontinuities in observed structures. However, the analysis of these changes requires taking into account the various characteristics of the examined object, since their exclusion may lead to significant measurement errors. Tested objects, supercapacitors, are to be classified as complex structures that are influenced by many different factors, which are the result both: used materials and production processes. The above mentioned factors may lead to the formation of different fluctuations in the observed temperature field. Therefore, the thermographic imaging of the surface allows, in non-destructive way, for characterization on the basis of recorded temperature fluctuations. It is due to the fact the temperature fields generated inside are the result of losses arising from charging and discharging processes at the substitute ESR. The observed fluctuations of this field arise mainly from those modifications, which, as a result of the degradation processes, are changing (usually the increase of the ESR value along with the degradation of the tested structure). Construction, properties, substitute models of supercapacitors, and modelling of temperature flows were inter alia discussed in the papers [2-6]. Suggested in the article proposal for using thermographic techniques in order to evaluate the condition of supercapacitors does not exhaust the subject. In a list of publications, inter alia in [7-9], were shown various non-destructive techniques, which, after proper implementation, may be applied 
to assessment. The applied measurement system, methodology of sample preparation, and used methods of analysis, as well as the results of taken tests, are described below.

\section{Applied Measurement System and Description of Samples}

Thermographic measurements, despite their simplicity, require good preparation of both: the sample and the appropriate test stand. The test stand should provide adequate stability and protection against environmental impact that may significantly influence the results of observations. VIGOcam v.50 (VIGO System S.A, Ozarow Mazowiecki, Poland) thermal imaging camera was used for the measurements. Its basic technical parameters are presented in Table 1.

Table 1. Relevant parameters of VIGOcam v.50 camera [10].

\begin{tabular}{cc}
\hline Parameter & Value/Function Description \\
\hline Detector type & Non-cooled bolometric matrix \\
Spectrum range & $8 \div 14 \mu \mathrm{m}$ \\
Image resolution & $384 \times 288$ \\
Thermal resolution & $\leq 0.065^{\circ} \mathrm{C}\left(\right.$ for temperature $\left.30^{\circ} \mathrm{C}\right)$ \\
Field of vision & $15^{\circ} \times 11^{\circ}$ \\
\hline
\end{tabular}

In order to isolate test objects from external impacts, while taking tests, they were placed in a casing that was protecting them against direct effects of other external temperature fields. The inner surfaces of the protective casing were covered with a graphite layer in order to minimize reflections and to stabilize the emissivity of the background at a constant level. It was done because one of the basic problems is the variability of the emission factor $(\varepsilon)$ of the tested objects, which is due to the secondary physical properties of the tested samples (such as the structure of the emitting surface, radiation angle, wavelength or temperature of the object). The above mentioned properties can significantly change the emissivity in the analyzed area. At the same time, it is known that the emissivity of metals increases along with the temperature rise, and in case of nonmetals, it decreases [11]. Therefore, the value of emissivity stability of the tested object is a prerequisite for proper temperature measurement when using thermal imaging cameras [12]. The emissivity coefficient is taking values between 0 and 1 .

For tests were chosen Samxon's DRL106SOTI25R supercapacitors (Man Yue Electronics Company Limited, Hong Kong, China) that are characterized by a variable structure (texture) of the observed surface (Figure 1). Their main technical data can be found in Table 2.

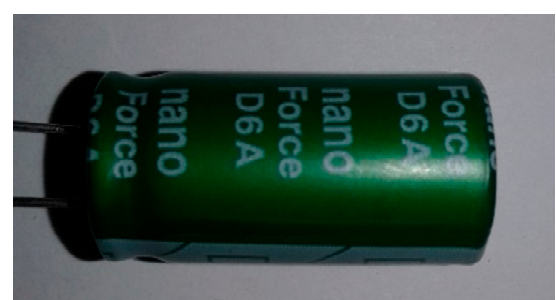

(a)

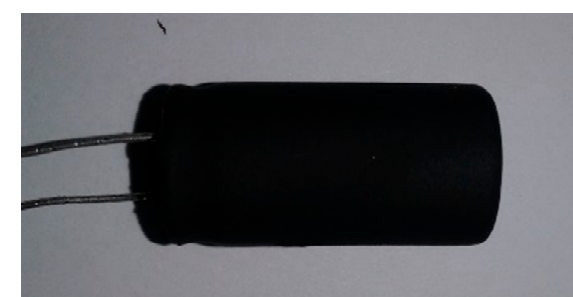

(b)

Figure 1. Photo of tested capacitors, (a) without graphite coating; (b) with graphite coating.

Table 2. Basic parameters of tested capacitors 4 [13]. ESR: equivalent series resistance.

\begin{tabular}{cccccc}
\hline $\begin{array}{c}\text { Rated } \\
\text { Voltage }\end{array}$ & $\begin{array}{c}\text { Rated } \\
\text { Capacitance }\end{array}$ & $\begin{array}{c}\text { Size } \boldsymbol{\Phi} \boldsymbol{D} \\
\times \boldsymbol{L}\end{array}$ & Max ESR & $\begin{array}{c}\text { Maximum Continues } \\
\text { Current }\left(\boldsymbol{\Delta} \boldsymbol{T}=\mathbf{1 5}{ }^{\circ} \mathbf{C}\right)\end{array}$ & $\begin{array}{c}\text { Cycles at Constant } \\
\text { Current }\left(\mathbf{2 5}{ }^{\circ} \mathbf{C}\right)\end{array}$ \\
\hline $\mathrm{V}$ & $\mathrm{F}$ & $\mathrm{mm}$ & $\mathrm{m} \Omega$ & $\mathrm{mA}$ & - \\
2.7 & 10 & $12.5 \times 25$ & 140 & 1400 & 500,000 \\
\hline
\end{tabular}


With the purpose minimizing the impact of surface structure changes, it was decided to cover the supercapacitor with a graphite layer (Graphite 33 from Contact Cheme). Then, the emissivity $(\varepsilon)$ was measured in relation to the available reference field, which allowed for the temperature measurement and had the known emissivity $\varepsilon \approx 0.96$. Technical measurements of the emissivity coefficient variation, in the assumed range of temperature increments $\left(\Delta T=25^{\circ} \mathrm{C}\right)$, were also performed. Samples, in the tested scope, were characterized by emissivity coefficient of emissivity $\varepsilon \approx 0.80$. Furthermore, it was decided to place the model reference field in the observation field of thermographic camera and to perform the procedure of nonuniformity correction (NUC) before taking each thermorgraphic image. Based on parameters of the camera that is included in [10] and publications [12], the uncertainty of determining temperature increments $(\Delta T)$ was estimated at $\sim 210 \mathrm{~m}{ }^{\circ} \mathrm{C}$. Atlas-Solitech (Multichannel Potentiostat Galvanostat) module was used to force charging/discharging processes in the tested capacitor samples. This module is able to perform both: power and measurement functions to record the present conditions of the test [14].

Figure 2 shows a schematic diagram of the applied test stand.

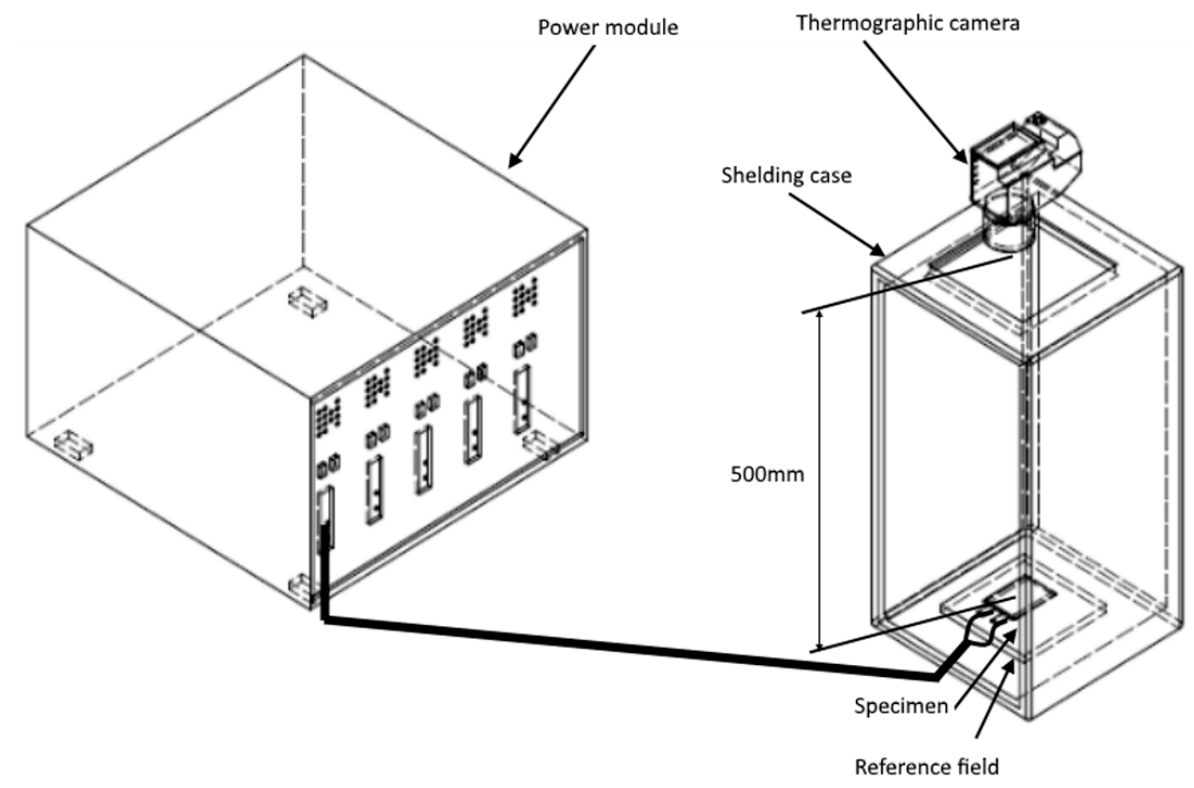

Figure 2. Schematic diagram of the applied test stand.

In order to minimize external influences, it was decided to determine the temperature increments in relation to the available reference field. Such an approach enabled the most effective use of the thermal resolution of the available measurement equipment. It needs to be bear in mind that thermographic methods are characterized by a considerable error when it comes to determining the temperature. For the used equipment it was estimated at $\pm 2.5^{\circ} \mathrm{C}$ (without reference field in the observed area).

The applied test methodology consisted of the following processes (stages) Figure 3:

- pre-conditioning to bring the sample to the state of thermodynamic equilibrium without thermographic measurements;

- thermographic measurements without powering (stage 1);

- thermographic measurements in the period of charging/discharging process (stage 2); and,

- thermographic measurements while cooling to the ambient temperature (stage 3). 


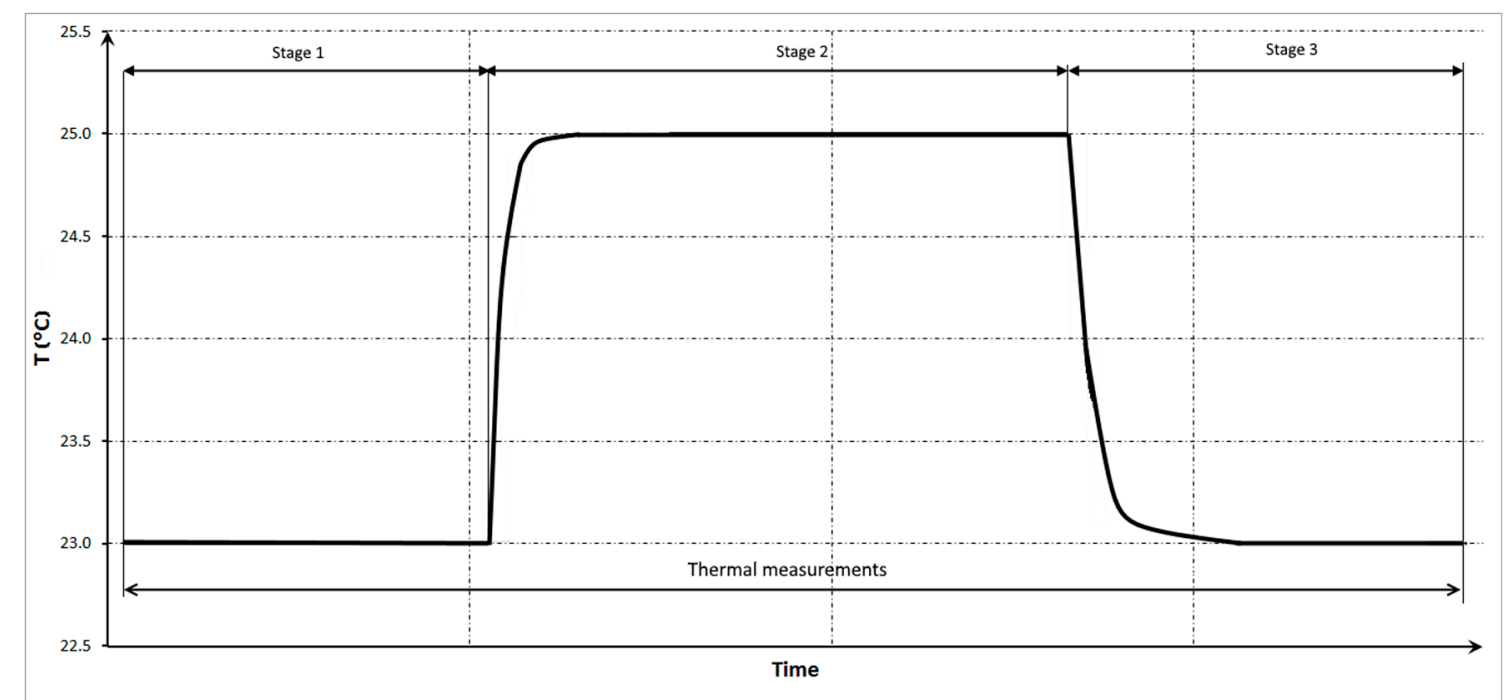

Figure 3. Schematic diagram of the applied test stand.

The applied power supply and measurement system during stage 2 recorded also the power supply parameters of the tested objects.

The applied measurement method assumes that the test initiates at the thermal equilibrium state without inducing current with the transition to thermal equilibrium while operating, and allows to estimate both the average $\left(\Delta T_{A v}\right)$ and the maximum temperature increment $\left(\Delta T_{M a x}\right)$ on the surface of the examined samples (observed area) depending on the inducted current. In order to achieve the state of temperature stability, while conducting the tests, it is necessary to perform at least 10-30 measurements in stage 1 and 100 to 200 measurements in stage 2. Additionally, it was assumed that the reference field should be placed in the observation field in order to control the measurement conditions. It was as well presumed to perform thermographic measurements with a fixed period time between the images taken from stage 1 to stage 3 . Due to the supposed slow variation of overheating processes, a measurement time interval of $60 \mathrm{~s}$ was proposed.

\section{Applied Methods of Analysis and Assessment of Supercapacitors}

In the course of tests, thermal images (B) representing the observed surfaces were obtained. The recorded measurement series consists of $N$ images, which were achieved with a fixed measurement period time. During the recording, a matrix, consisting of $N$ measurements having a size of $388 \times 288$ data on observed temperatures was obtained. The data on the thermographic assessment of tested samples was analyzed in an off-line manner according to the algorithm presented below in Figure 4.

On this basis, images showing variability in the parameters of the observed area were achieved. Both the variability of the parameter, as an observation function of time, as well as its changes in the observed area were obtained. Figure 5 presents determined maximum changes in the temperature increment $\left(\Delta T_{M a x}\right)$ during test (stage 1-3) for the capacitor sample when operating at a supply voltage of $U=2.7 \mathrm{~V}$, at $I=1400 \mathrm{~mA}$, for $N=230$ images recorded. Figure 6 illustrates a sample single image, which was obtained at $150 \mathrm{~min}$ for the second measurement stage. 


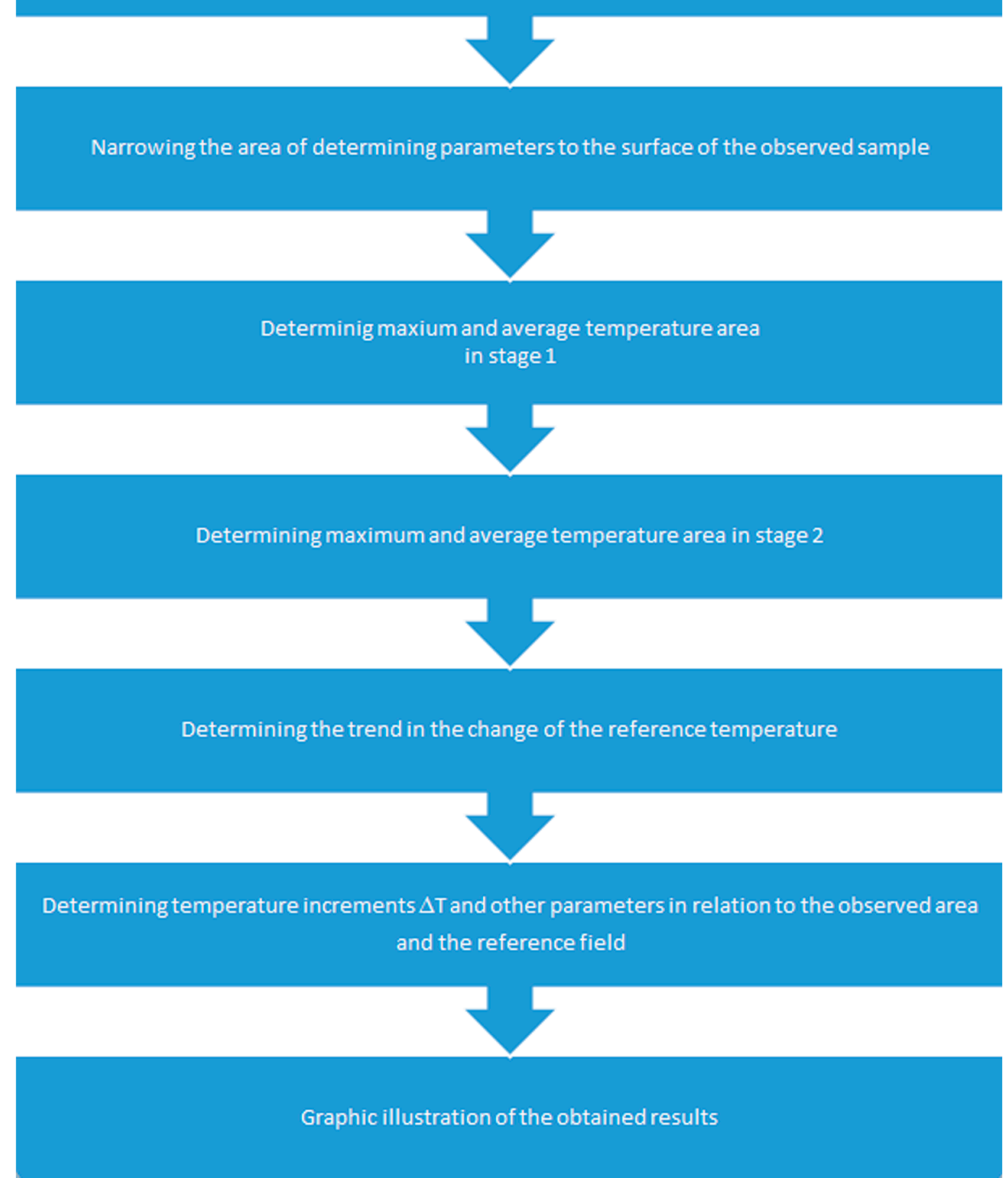

Figure 4. Graph of the algorithm used to determine thermal parameters.

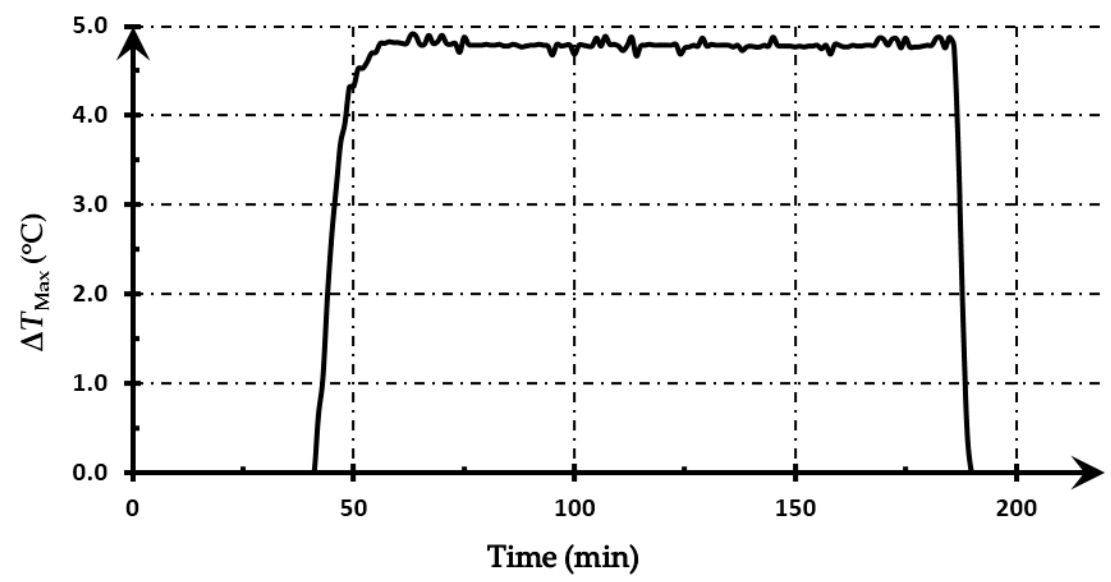

Figure 5. The course of changes of maximum temperature increment $\Delta T_{\operatorname{Max}}$ on the surface of the observed sample during the test. 


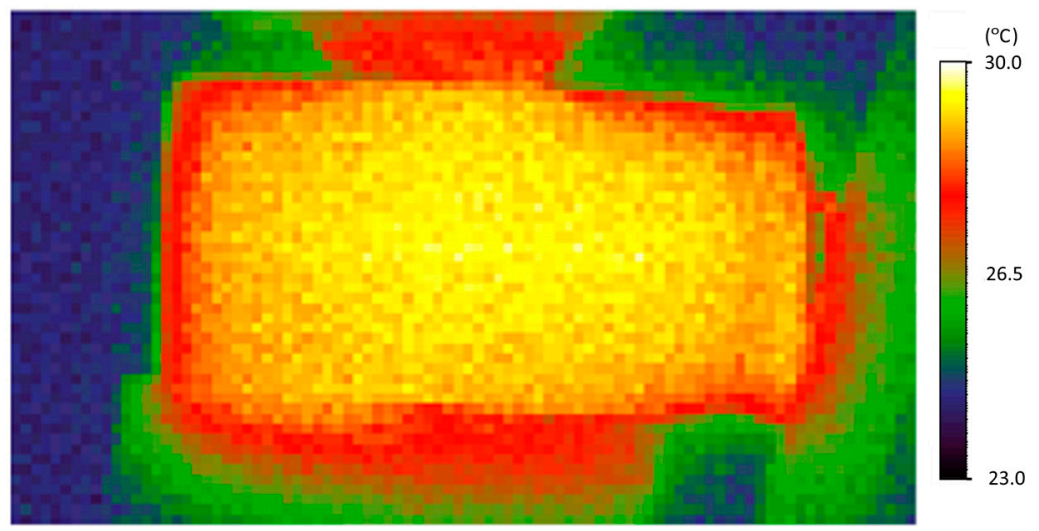

Figure 6. Typical image of a single sample thermogram during the test process for $U=2.7 \mathrm{~V}$, $I=1400 \mathrm{~mA}$.

Following parameters were selected for the preliminary tests to support the qualitative assessment of the measurement results:

- the average temperature increment $\left(\Delta T_{A v}\right)$ of the observed area during the second stage (during the charging/discharging process) in relation to the average temperature of the observed surface during the first stage (without powering) allows to estimate the temperature rise $\left(\Delta T_{A v}\right)$ depending on the current of the tested supercapacitor;

- maximum temperature increase $\left(\Delta T_{M a x}\right)$ of the observed surface during the second stage (during the charging/discharging process) in relation to the average temperature of the observed surface during the first stage (without powering); and,

- standard deviation of average temperature increment $(\sigma)$. Allows to estimate the variation in charging/discharging process during the test.

In addition, throughout the test, were implemented ancillary parameters, whose functionality (usability) was tested, such as:

- temperature sum of individual images $(\Sigma T)$. The obtained final image is the sum of all recorded $N$ thermographic measurements. It allows to indicate the area where the most extreme temperature change occurs, however, it depends on the ambient temperature; and,

- the process coefficient of variation $(\mathrm{CV})$, as defined by the Equation (1):

$$
C V=\frac{v a r_{T}}{\Delta T_{A v}}
$$

where:

var $_{T}$ - temperature variance during observation

$\Delta T_{A v}$-average temperature in the second stage of observation

It was presumed that the above mentioned parameters would allow to obtain additional information, which is included in the standard deviation graph, allowing for the better estimation of the fluctuation of the temperature field during observation of the selected area. At the same time, information, in the graphical form concerning the distribution of maximum and average temperature increments during the test for a given surface, allows to determine whether processes that are occurring within the examined object are homogenous. Additionally, during the test, data enabling to refer to previously used classifications allowing for the evaluation of supercapacitors samples were collected and monitored. Assessment methods so far used have been described in [15,16], and include inter alia: cyclic voltammetry, constant current charging/discharging, impedance spectroscopy, accelerated aging test. Above mentioned methods allow for the supercapacitor to be assessed 
on the basis on the recording of currents and voltages occurring during the test. The constant current charging/discharging method that is used in this test, despite the necessity of long-term observation, is most closely related to the actual operating conditions of the capacitors and is subjected to fluctuations in the temperature field of the tested capacitor due to its operating conditions. In supercapacitors' tests, calorimetric systems are generally used to determine maximum temperature increments, however, despite their high accuracy, they do not allow the heterogeneity of the sample to be displayed as described in articles $[3,4,17]$. Throughout tests, in which the proposed method was used, the following parameters of the power supply system were also monitored:

- the power stored during the test expressed in (mAh);

- voltage on the test sample expressed in $(\mathrm{V})$; and,

- current in the course of test expressed in (mA).

The above parameters allowed to determine in the off-line processing the influence of the conducted test on the change of capacities $(C)$ and ESR and to verify whether the sample was subject to change as a result of the test. Those parameters were determined on the basis of recorded data. Figure 7 illustrates the theoretical voltage waveform present during the test with the use of constant current charging/discharging method.

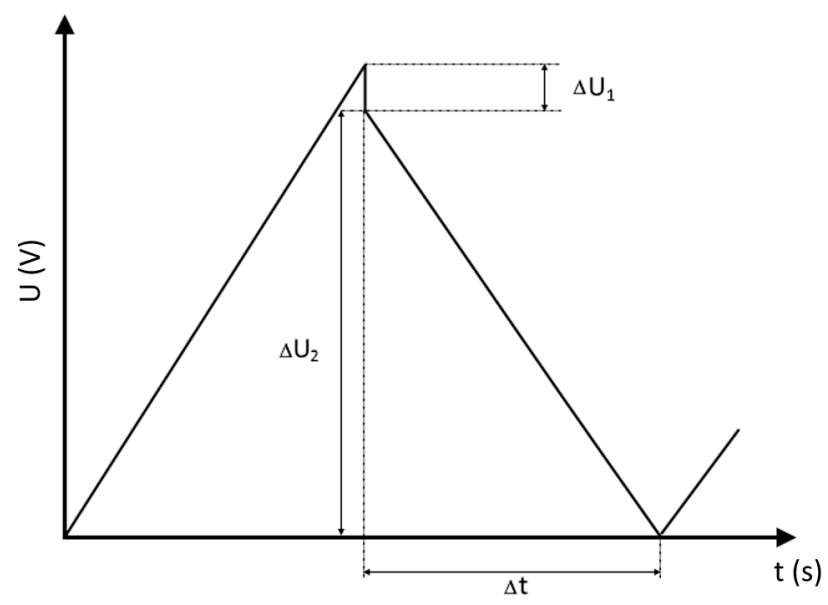

Figure 7. An image of an ideal charging/discharging process on the basis of which the parameters of the supercapacitor were determined.

The collected data allowed to estimate the capacity of the test sample on the basis of the Equation (2):

$$
C=\frac{I_{d} \cdot \Delta t}{\Delta U_{2}}
$$

and ESR based on the Equation (3):

$$
E S R=\frac{\Delta U_{1}}{\left|I_{d}\right|}
$$

where:

$I_{d}$-test current (charging/discharging),

$\Delta t$ - discharging time,

$\Delta U_{1}$-voltage drop on $E S R$, and

$\Delta U_{2}-$ voltage drop during the discharging process.

It should be noted here, that in real systems, the voltage waveforms are not described accurately by linear waveforms, although, in most studies the nonlinearity is omitted. The condition necessary to estimate the quality is to adopt criteria for its evaluation. The basic criteria that are currently used for 
assessment are: the change in capacity $(C)$ and ESR value. The change in capacity $(C)$ by $20 \%$ and/or ESR increase by $+100 \%$ over the initial value, under the recommendations of $[4,5]$, has been taken as the criterion of exclusion. Such types of tests are characterized by a very long period of performance, while performed with ratings (they are classified as long-term tests). Currently produced capacitors are characterized, inter alia, by guaranteed durability of at least 500,000 charging/discharging cycles at rated current and voltage [17]. In order to accelerate the occurrence of the aging phenomena in the tests, it was decided to exceed the nominal values that were recommended by the manufacturer of the capacitor, assuming as a critical value the average temperature increment $\left(\Delta T_{A v}\right)$ that should be less than $15^{\circ} \mathrm{C}$ for the observed supercapacitor surface [13].

\section{Selected Measurement Test Results}

Two specimen number 1 and number 2 were tested, according to the method described above, in two measurement series at an ambient temperature of $25^{\circ} \mathrm{C} \pm 5{ }^{\circ} \mathrm{C}$. Initial measurements were taken at rated supply voltages and up to nominal charging/discharging currents. In the second stage, measurements with voltages and currents that were exceeding the predicted values were made to accelerate the occurrence of aging phenomena. The acceleration was applied due to the time consuming method of constant current charging/discharging at nominal parameters of supercapacitor (declared lifetime of more than 500,000 cycles at nominal values at $25^{\circ} \mathrm{C}$ ).

For instance, Figure 8 illustrates the graph of maximum temperature increments $\left(\Delta T_{M a x}\right)$ on the observed surface of supercapacitor at rated capacitor values of $U=2.7 \mathrm{~V}, I=1400 \mathrm{~mA}$ for which no changes in capacitor parameters were noted and the maximum test temperature was approximately $\Delta T_{\text {Max }}=5^{\circ} \mathrm{C}$.

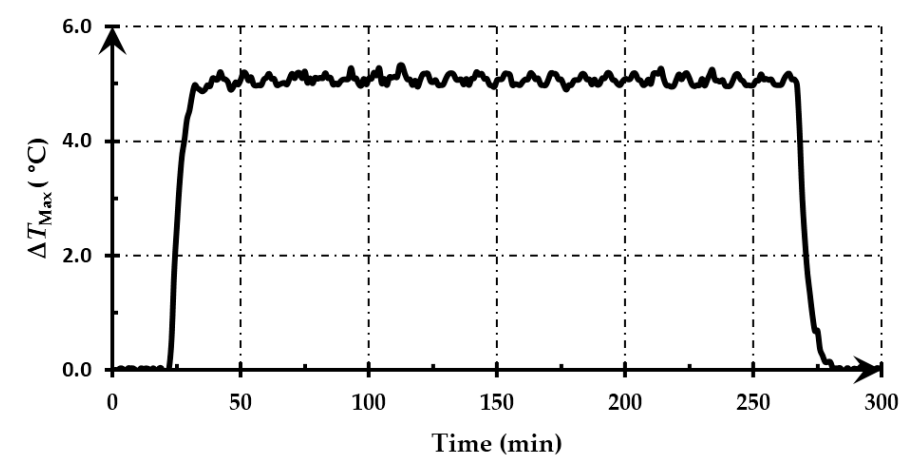

Figure 8. Maximum temperature increments $\Delta T_{\text {Max }}$ of supercapacitors at voltage $U=2.7 \mathrm{~V}$ and current $I=1400 \mathrm{~mA}$ (nominal conditions).

Second stage tests with overruns of nominal values have been presented in Figure 9 a thermogram for tests with voltage $U=3.3 \mathrm{~V}$ and current $I=2800 \mathrm{~mA}$.

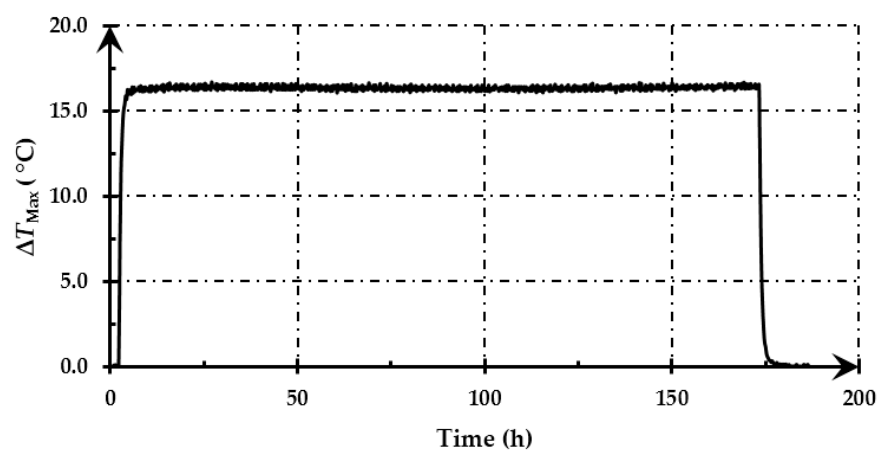

Figure 9. Chart of maximum temperature increments $\Delta T_{M a x}$ change during test $U=3.3 \mathrm{~V}, I=2800 \mathrm{~mA}$. 
Simultaneously taken measurements of the characteristic parameters $(C)$ and ESR shown in Figure 10 displayed no changes (Figure 10 for $\sim 450$ cycles).

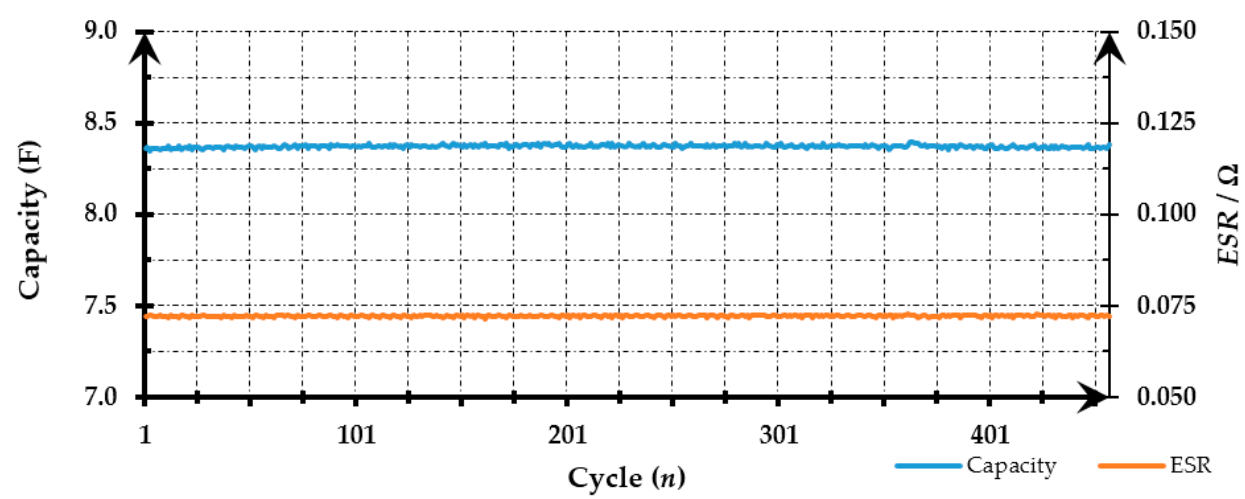

Figure 10. Charts illustrating variation in capacity $(C)$ and equivalent series resistance $(E S R)$ values during test $U=3.3 \mathrm{~V}, I=2800 \mathrm{~mA}$.

Variations in characteristic values of tested supercapacitors were observed after around 700 cycles with the test parameters: $U=3.6 \mathrm{~V}, I=3200 \mathrm{~mA}$, as illustrated in Figure 11 .

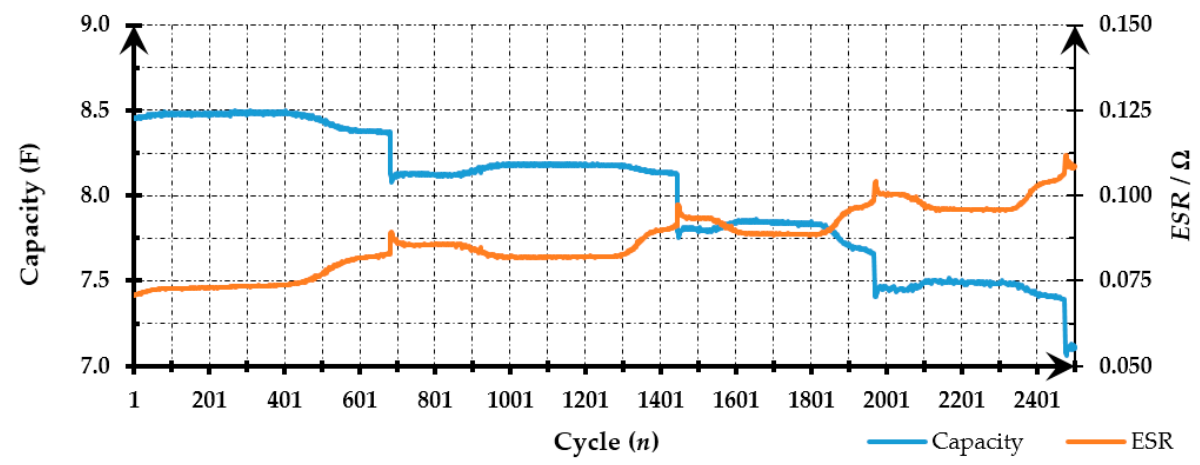

Figure 11. Chart presenting variation of capacity $(C)$ and $E S R$ during test $U=3.6 \mathrm{~V}, I=3200 \mathrm{~mA}$.

Observed variations in capacity $(C)$ and ESR were accompanied by an increase in maximum temperature increments $\left(\Delta T_{M a x}\right)$ which were increasing along with $E S R$ increment, as shown in Figure 12.

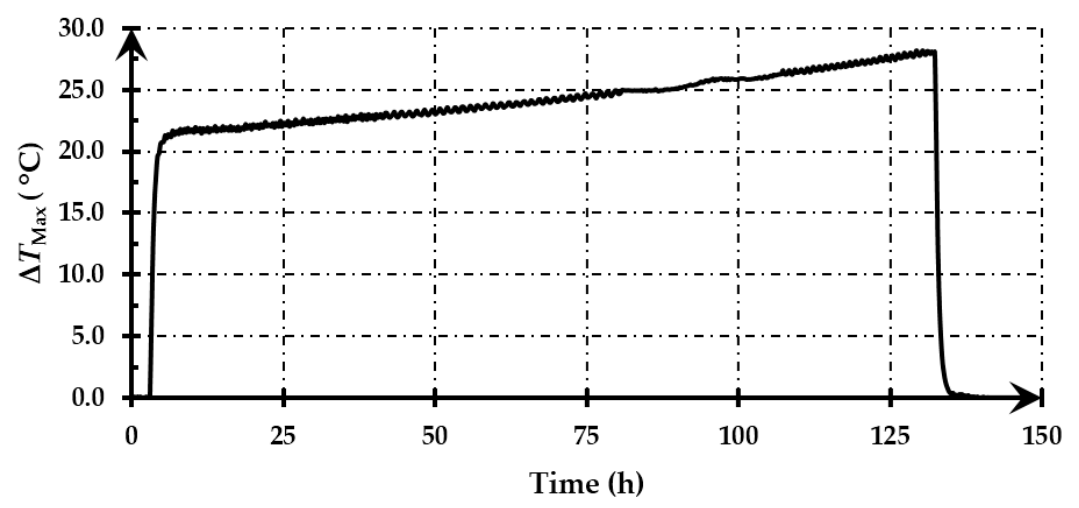

Figure 12. Chart showing variation of maximum temperature increments maximum temperature increment $\left(\Delta T_{\text {Max }}\right)$ during test $U=3.6 \mathrm{~V}, I=3200 \mathrm{~mA}$. 
Figure 13 presents the temperature field distribution for the picture taken in $101 \mathrm{~h}$ of the test for the test at voltage $U=3.6 \mathrm{~V}$ and current $I=3200 \mathrm{~mA}$.

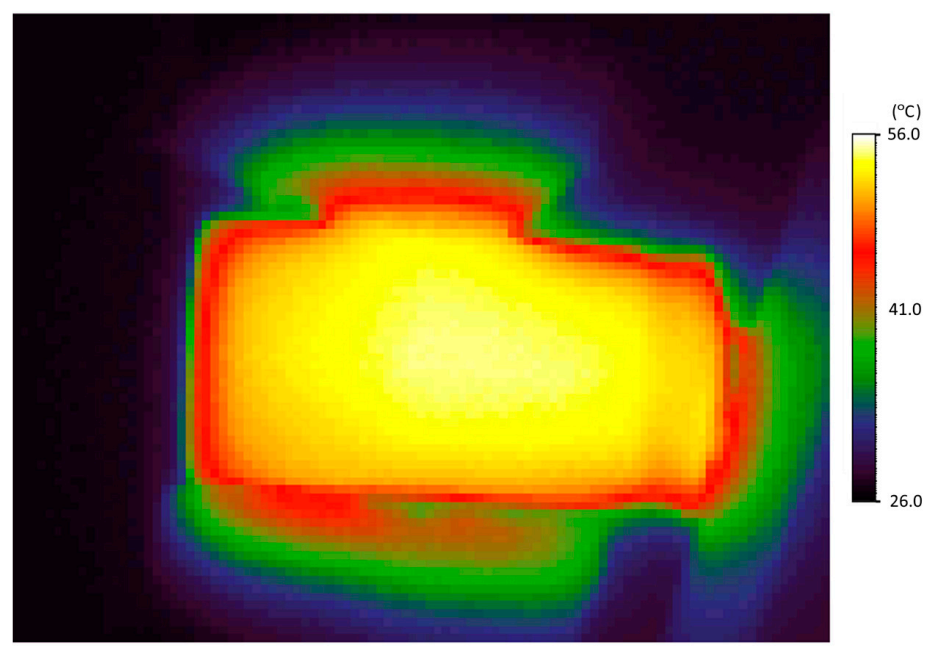

Figure 13. Distribution of supercapacitor temperature field at voltage $U=3.6 \mathrm{~V}$ and current $I=3200 \mathrm{~mA}$.

Figure 14 illustrates the results of the average temperature increments $\left(\Delta T_{A v}\right)$ of all the observed samples as a function of current, for which no changes in the capacities $(C)$ and ESR occurred during the test. Changes in the values of maximum temperature increments $\left(\Delta T_{M a x}\right)$, as a function of currents, are demonstrated in Figure 15.

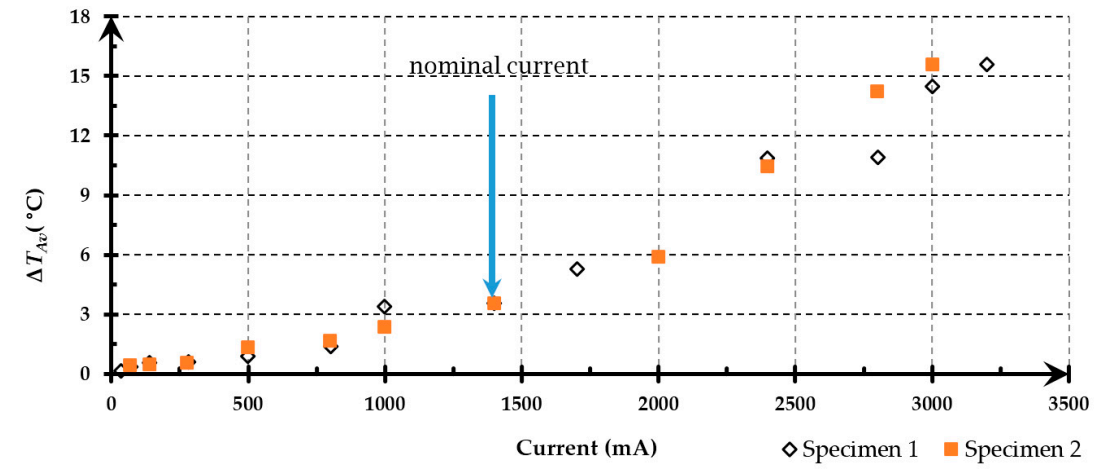

Figure 14. Average surface temperature increments $\left(\Delta T_{A v}\right)$ of tested supercapacitors as a function of current.

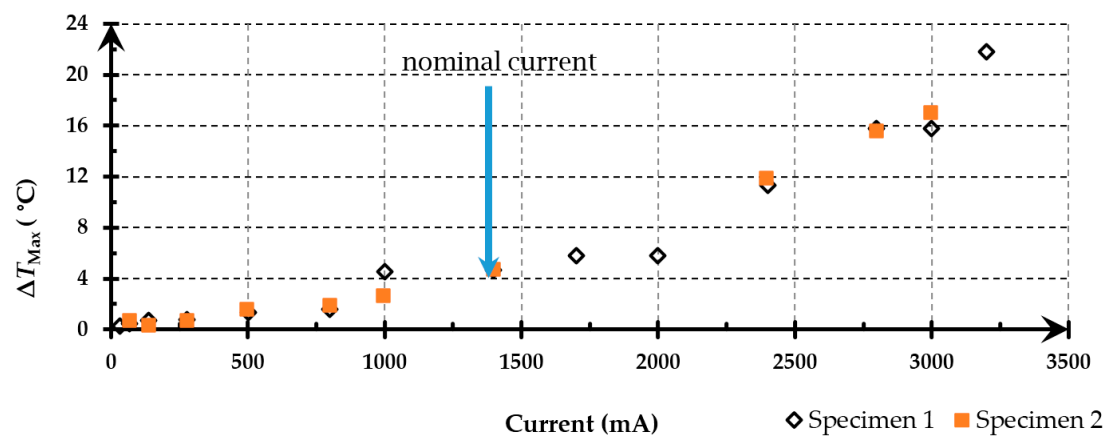

Figure 15. Maximum surface temperature increment $\left(\Delta T_{M a x}\right)$ of tested supercapacitor as a function of current. 
Figure 16 shows a graphical representation of the standard deviation $\sigma$ obtained during the test of samples at the test values $U=2.7 \mathrm{~V}, I=500 \mathrm{~mA}$, and at the test values $U=2.7 \mathrm{~V}, I=1400 \mathrm{~mA}$.

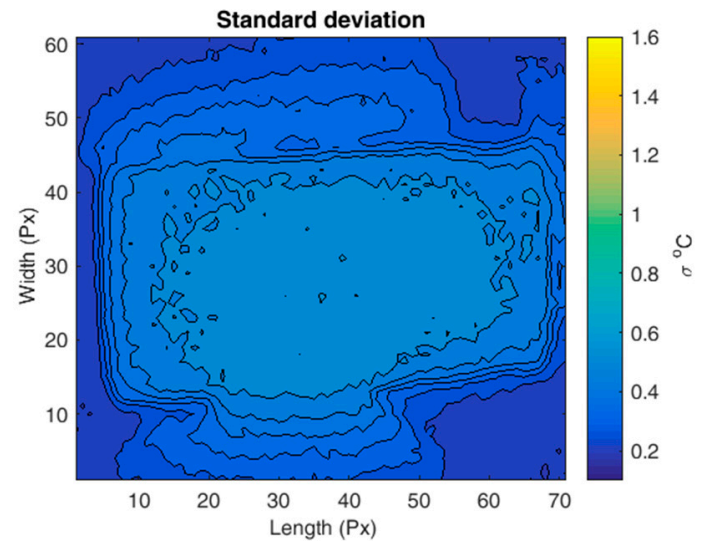

(a)

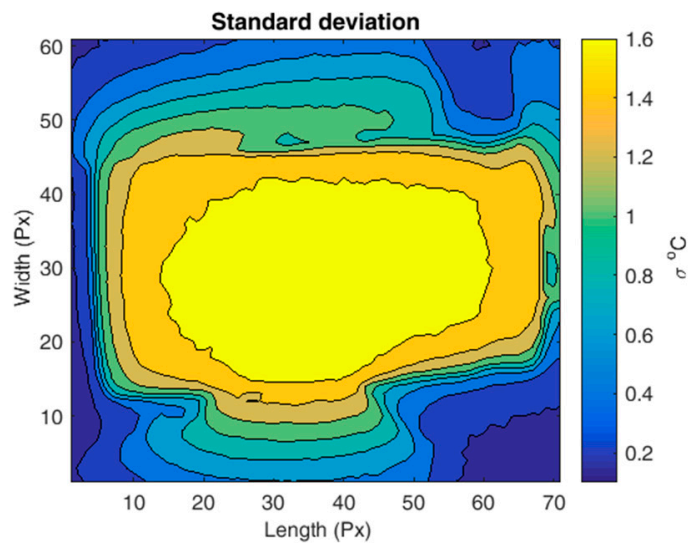

(b)

Figure 16. Graphic display of standard deviation changes for: (a) test parameters $U=2.7 \mathrm{~V}$ and $I=500 \mathrm{~mA}$; (b) test parameters $U=2.7 \mathrm{~V}$ and current $I=1400 \mathrm{~mA}$.

In addition, Figure 17 depicts the instantaneous values obtained for ancillary parameters (sum of temperatures $\Sigma T$ and coefficient of variation $C V$ ) to illustrate the condition of the sample for the test value $U=3.6 \mathrm{~V}, I=3200 \mathrm{~mA}$, for which occurred changes in the determined parameters.

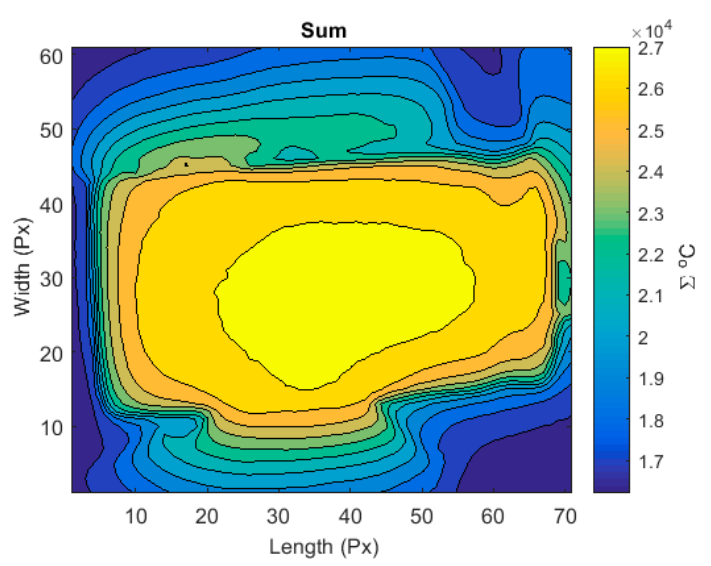

(a)

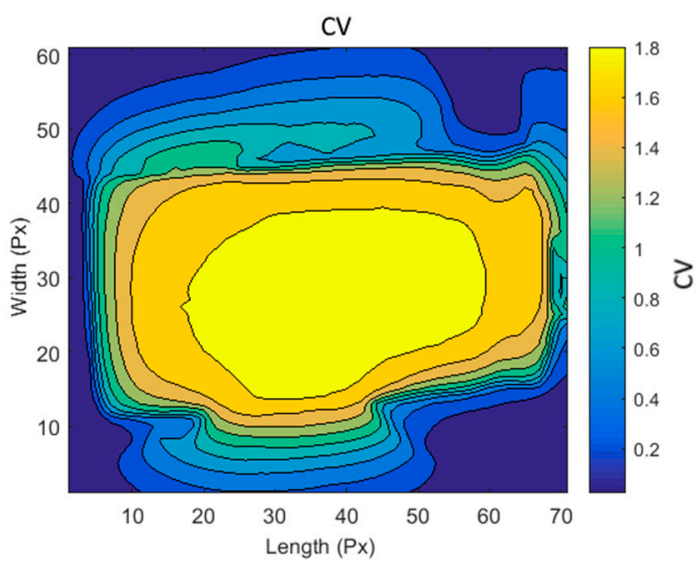

(b)

Figure 17. (a) Image of sum of temperatures $(\Sigma T)$; (b) Image of the coefficient of variation $(C V)$.

\section{Conclusions}

The measurements indicate that the application of thermographic observation of the examined objects allows for extending the assessment of their condition (quality). An additional evaluation of temperature fields of the tested sample allows to obtain information about inside processes and, on the basis of analysis of the thermographic data, to gather information about its current condition. One of the basic parameters that was used to determine the condition of a given object is the maximum temperature increment. The assessment based on temperature increment can be carried out on both levels: the producer and the end user, and it does not require the use of particularly specialized equipment. The obtained thermal parameters indicate that while operating with the nominal values of currents and voltages, the samples are characterized by maximum temperature increments $\left(\Delta T_{M a x}\right)$ of $5{ }^{\circ} \mathrm{C}$. On the other hand, obtained records of temperature increments of up to $15^{\circ} \mathrm{C}$ with currents and voltages above the rated values showed no changes in the electrical parameters of the supercapacitors 
that were tested up to 3000 cycles (about eight days for $U=3.3 \mathrm{~V}$ and $I=2800 \mathrm{~mA}$ ). On the other hand, in case of recording temperature increments above $20^{\circ} \mathrm{C}$, it can be assumed that the observed element changes its parameters. The recorded changes occurred abruptly only when the nominal values were exceeded. Additionally, it should be noted that tested supercapacitors showed significant changes in their parameters only when working with voltages and currents that were significantly exceeding nominal values. In tested samples, only the increase of both voltage and current caused the change of parameters. According to the author, supercapacitors are less resistant to changes in voltage than to changes in current. The research results show that the voltage change over $\sim+30 \%$ and the current change $\sim+120 \%$ above the nominal value caused changes in electrical parameters after about 700 cycles (after about $2 \mathrm{~h}$ of testing). At the same time, tests with voltages above $\sim+20 \%$ and currents $\sim+100 \%$ exceeding the nominal value in the period after about 3000 cycles (after about eight days) showed no changes in electrical parameters. The conducted verification of the proposed methodology has shown that thermographic measurements, despite the lower accuracy of the measurement than the calorimetric tests, have the additional ability to show the distribution of the temperature field and its fluctuation in the form of graphical distribution on the observed surface. What is more, there is an additional possibility for observing changes in the temperature field on a regular basis during the conducted research and with the possibility of further interpretation and analysis (off-line). The proposed methodology research with the use of thermography seems to be useful particularly in the field of research and development works focusing on supercapacitors. At the same time, the assumed sum of temperatures $(\Sigma T)$, which was used in the graphic representation of the observed surface, allows the indication of the area in which the most intensified heat generation occurs and to indicate the areas of heat generation during the test. Additionally, the measurements show that the proposed coefficient of variation $(\mathrm{CV})$, which is used to support the graphical analysis of the results by indicating areas with the highest variability of the processes occurring on the observed surface, provides similar information such as the sum temperature $(\Sigma T)$ coefficient. It points the area where the temperature increment occurs over the entire observed period. Therefore, in case of observing supercapacitors in the classical folded form, it seems to be unreasonable to use the coefficient of variation $(\mathrm{CV})$ as there appears the redundancy of obtained results. On the basis of obtained results, it can be concluded that in the case of tested samples of supercapacitors, it is better to have an uncoil capacitor than a fully folded one, as one is commercially available on the market. For design-development research, it is assumed that prototypes of supercapacitors are made in the form of envelopes, which will make a better use of the available resolution of the camera. The proposal for measuring the supercapacitors in the form of flat rectangular envelopes results from the intention to observe areas of electrical outlets. In case of a classical supercapacitor in a folded form, the individual layers overlap and are additionally placed in a cylindrical cover. Hence, the thermographic image that is obtained during the testing of such samples is the interaction of the individual layers. The recorded thermographic images are the sum of all the changes. Therefore, local changes cannot be seen in deeper layers. The production of supercapacitor samples in the form of envelopes will make it easier to observe processes inside. This applies particularly to electrical outlets that are largely responsible for overheating. In addition, it needs be noted that the whole process of assessing the usefulness of supercapacitors should be evaluated in greater detail. The assessment by means of extended criteria can be a tool supporting developmental research and can be helpful in determining properties of supercapacitors. In order to obtain a fuller spectrum of information about a particular structure, a number of other parameters, which can significantly influence the properties and describe them more accurately, should be checked. The obtained data indicates that the tested samples of commercial supercapacitors are characterized by a high durability, while operating with rated nominal values of currents and voltages. The tested research-measurement methods will be applied to the research that was conducted by the author on the development of the construction of supercapacitors within the next project. 
Acknowledgments: This paper is financially supported by the National Science Centre Poland, project No. DEC-2014/15/B/ST4/04957, "Charging/discharching mechanism at the electrode/electrolyte interface of supercapacitors" decision of 11.05.2015.

Conflicts of Interest: The authors declare no conflict of interest.

\section{References}

1. Pascot, C.; Dandeville, Y.; Scudeller, Y.; Guillemet, P.; Brousse, T. Calorimetric measurement of the heat generated by a Double-Layer Capacitor cell under cycling. Thermochim. Acta 2010, 510, 53-60. [CrossRef]

2. Sharma, P.; Bhatti, T.S. A review on electrochemical double-layer capacitors. Energy Convers. Manag. 2010, 51, 2901-2912. [CrossRef]

3. Guillemet, P.; Pascot, C.; Scudeller, Y. Electro-thermal analysis of Electric Double-Layer-Capacitors. In Proceedings of the 14th International Workshop on Thermal Inveatigation of ICs and Systems, Rome, Italy, 24-26 September 2008; pp. 224-228.

4. Wang, K.; Zhang, L.; Ji, B.; Yuan, J. The thermal analysis on the stackable supercapacitor. Energy 2013, 59, 440-444. [CrossRef]

5. Arkadiusz, S.; Josef, S.; Vlasta, S.; Jiri, M.; Petr, S.; Tomas, K. Voltage Dependence of Supercapacitor Capacitance. Metrol. Meas. Syst. 2016, 23, 403-411. [CrossRef]

6. Kuparowitz, M.; Sedlakova, V.; Grmela, L. Leakage Current Degradation Due to Ion Drift and Diffusion in Tantalum and Niobium Oxide Capacitors. Metrol. Meas. Syst. 2017, 24, 255-264. [CrossRef]

7. Farhidzadeh, A.; Dehghan-Niri, E.; Moustafa, A.; Salamone, S.; Whittaker, A. Damage Assessment of Reinforced Concrete Structures Using Fractal Analysis of Residual Crack Patterns. Exp. Mech. 2013, 53, 1607-1619. [CrossRef]

8. Kiwilszo, M.; Smulko, J. Pitting corrosion characterization by electrochemical noise measurements on asymmetric electrodes. J. Solid State Electrochem. 2009, 13, 1681-1686. [CrossRef]

9. Poozesh, P.; Sarrafi, A.; Mao, Z.; Niezrecki, C. Modal parameter estimation from optically-measured data using a hybrid output-only system identification method. Measurement 2017, 110, 134-145. [CrossRef]

10. VIGOcam v50.pdf. Available online: https://www.vigo.com.pl/pub/File/PRODUKTY/Thermal-imagingsystem/v50.pdf (accessed on 6 October 2017).

11. Vollmer, M.; Mollmann, K.-P. Infrared Thermal Imaging: Fundamentals, Research and Applications; John Wiley \& Sons: Hoboken, NJ, USA, 2010; ISBN 978-3-527-40717-0.

12. Minkina, W.; Dudzik, S. Infrared Thermography: Errors and Uncertainties; John Wiley \& Sons: Hoboken, NJ, USA, 2009; ISBN 978-0-470-68224-1.

13. Edlc_catalogue.pdf. Available online: http://www.manyue.com/edlc_catalogue.pdf (accessed on 6 October 2017).

14. ATLAS 1361 Multichannel Potencjostat Galwanostat i Tester. Available online: http://atlas-sollich.pl/ produkty /1361.htm (accessed on 6 October 2017).

15. Bohlen, O.; Kowal, J.; Sauer, D.U. Ageing behaviour of electrochemical double layer capacitors: Part I. Experimental study and ageing model. J. Power Sources 2007, 172, 468-475. [CrossRef]

16. Beguin, F.; Frackowiak, E. Supercapacitors: Materials, Systems and Applications; John Wiley \& Sons: Hoboken, NJ, USA, 2013; ISBN 978-3-527-64668-5.

17. Gualous, H.; Louahlia, H.; Gallay, R. Supercapacitor Characterization and Thermal Modelling with Reversible and Irreversible Heat Effect. IEEE Trans. Power Electron. 2011, 26, 3402-3409. [CrossRef]

(C) 2017 by the author. Licensee MDPI, Basel, Switzerland. This article is an open access article distributed under the terms and conditions of the Creative Commons Attribution (CC BY) license (http://creativecommons.org/licenses/by/4.0/). 